\title{
DESIGN AND PERFORMANCE EVALUATION OF PROTECTIVE CLOTHING FOR EMERGENCY RESCUE
}

\author{
Haitang Zhang ${ }^{1}$, Qing Zheng ${ }^{1}$, Ying Ke ${ }^{1, *}$, Hongfu Wang ${ }^{1}$, Min Wang ${ }^{2}$, Yuanli Ye ${ }^{3}$ \\ 1 Jiangnan University, Wuxi, China \\ 2 Key Laboratory of Clothing Design and Technology (Donghua University), Ministry of Education, Shanghai, China \\ 3 Swoto Protection Technology Co. LTD., Wuxi, China \\ *Corresponding author. Email: keying0312@163.com
}

\begin{abstract}
:
Protective clothing is very important to guarantee the safety of emergency rescuers. And proper construction design of clothing will improve the rescue efficacy. This study developed a new set of emergency rescue protective clothing (NC) and evaluated its performance. Clothing fit test, freedom of movement, and rationality of pocket tests were conducted. The results showed that the amount of slippage at the hem, waist of pants, and leg opening of NC has been greatly reduced. The NC had provided better cloth fit and dynamic comfort. The storage capacity of the pockets had been increased, the position and angle design of the pocket made it easier to take and keep the rescue tools.
\end{abstract}

\section{Keywords:}

Emergency rescue clothing; Structure design; Wearing comfort; Performance evaluation

\section{Introduction}

The intensity and frequency of natural and man-made global disasters have been growing in recent years [1, 2]. According to the report of the Swissre institute [3], the average global loss from natural and man-made disasters was as high as $\$ 212$ billion between 2010 and 2019 . The casualties of rescue workers are one of the practical problems to be solved. In China, there were 280 cases in which many rescuers lost their lives during rescue and more than 600 people were killed or injured, between the year of 1960 and 2014 [4]. Many factors are responsible for the casualties of rescue workers, such as risk assessment, emergency process supervision, rescue team quality, emergency rescue system, emergency linkage mechanism, and network public opinion influence [4, 5]. Individual protective equipment is one of the key aspects to guarantee the safety of rescue workers and improve the efficiency of on-site rescue [6].

Rescue workers have to face the dangerous situations when working under the disaster environment, where the rescue suit has a variety of functional properties, such as waterproof, anti-static, wear-resistant, and so on[7]. Unreasonable clothing design, especially the structure design may greatly hamper the body movements, thereby increasing the energy expenditure and causing serious injuries [8, 9]. In addition to environmental threats to the safety of rescue workers, unreasonable design of rescue clothing also has negative impacts on the human body, preventing heat loss, affecting metabolism, such as human activities, leading to the reduction of comfort, ultimately affecting the efficiency of rescue, and seriously threatening the safety of rescue workers $[10,11]$. Most of the available studies about protective clothing always focused on the development and improvement of special functions, especially on the application of new functional fabrics [12-14]. Only few studies focused on the construction design of the protective clothing for emergency rescuers.

At present, the protective clothing used in emergency rescue is ordinary work-wear with a placket structure and lapel, and usually made of T/C (polyester and cotton blend fabric) or pure cotton fabric. This traditional clothing has rough texture and low wearing comfort, and cannot provide protection in the complex environment of rescue sites. Hence, a new set of emergency rescue protective clothing was designed and its performance was evaluated in this study. Clothing fit, freedom of movement, and rationality of the newly clothing were tested to verify and evaluate the performance of the new emergency rescue protective clothing. It was hypothesized that the new emergency rescue protective clothing could significantly improve the freedom of movement and comfort of the emergency rescuers, compared to the traditional clothing worn at the emergency rescue site.

\section{Development of an emergency rescue protective clothing}

2.1. Analysis of traditional emergency rescue protective clothing (TC)

A set of traditional protective clothing (TC) used in emergency rescue was selected for this study. Figure 1 showed the design 
sketch of the TC. Measurements of the center back length, collar length, chest girth, shoulder across, sleeve length, inseam length, back rise, waist width, hip girth, and leg opening of the TC were $67.5 \mathrm{~cm}, 44 \mathrm{~cm}, 108 \mathrm{~cm}, 48 \mathrm{~cm}, 58.5 \mathrm{~cm}$, $101 \mathrm{~cm}, 37 \mathrm{~cm}, 80 \mathrm{~cm}, 108 \mathrm{~cm}$, and $46 \mathrm{~cm}$, respectively. The TC was made of $65 \%$ polyester and $35 \%$ cotton blended fabric with a $1 / 2$ twill structure which was not soft and not breathable. The clothing had two symmetrical patch pockets on the chest and a little pocket on the left sleeve of the jacket. Common buttons were designed at the placket, cuff and pocket cover, which is time-consuming to wear and take off. Hemline side seam position set symmetrical two loop buckle to adjust the hemline size. The pants were provided with an elastic belt at the waist. Apart from the slant pocket, there were symmetrical side pockets with cover on both sides of the pants, and a small bag was added above the left outer bag. Velcro was provided on the cuffs of the pants, to adjust the size of the leg opening. When analyzing the movements of rescue workers wearing traditional protective clothing during work, it was found that the forward bending of the arm causes serious deformation on the back of the garment and the tear on the crotch is more obvious when spanning. When squatting, there is a large demand for the ease of the knee and it is easy for the waist of the pants slip off. Similarly, bending often occur during the rescue process, which result in easy exposure of the skin of the waist.

\subsection{Design of the new emergency rescue protective clothing (NC)}

Figures 2 and 3 show the designed sketch and photos of the NC, respectively. The size of the NC was $175 / 96$ A [15]. The center back length, collar length, chest girth, shoulder across, sleeve length, inseam length, back rise, waist width, hip girth, and leg opening of the NC were $70 \mathrm{~cm}, 44 \mathrm{~cm}, 116 \mathrm{~cm}, 53 \mathrm{~cm}, 61.5 \mathrm{~cm}$, $101 \mathrm{~cm}, 41 \mathrm{~cm}, 80 \mathrm{~cm}, 105 \mathrm{~m}$, and $41 \mathrm{~cm}$, respectively. The NC was made of $65 \%$ polyester and $35 \%$ cotton blended fabric with a $1 / 2$ twill structure, but the fabric of NC is softer, lighter, and breathable. The basic parameters of the two clothing fabrics are shown in Table 1. The NC adopted the upper and lower split structure, which meet the requirements of the rescue workers' torsos during the rescue process [16]. Sleeve crotch was used in the armpit to increase the angle of upper limb movement and along with that two pieces of breathable mesh cloth were selected for the triangular insert of the armpit, overlapped but not stitched. The placket adopted a concealed placket structure, which not only make the placket plain and beautiful, but also prevent button hook and pull [17]. Since the rescuers need to
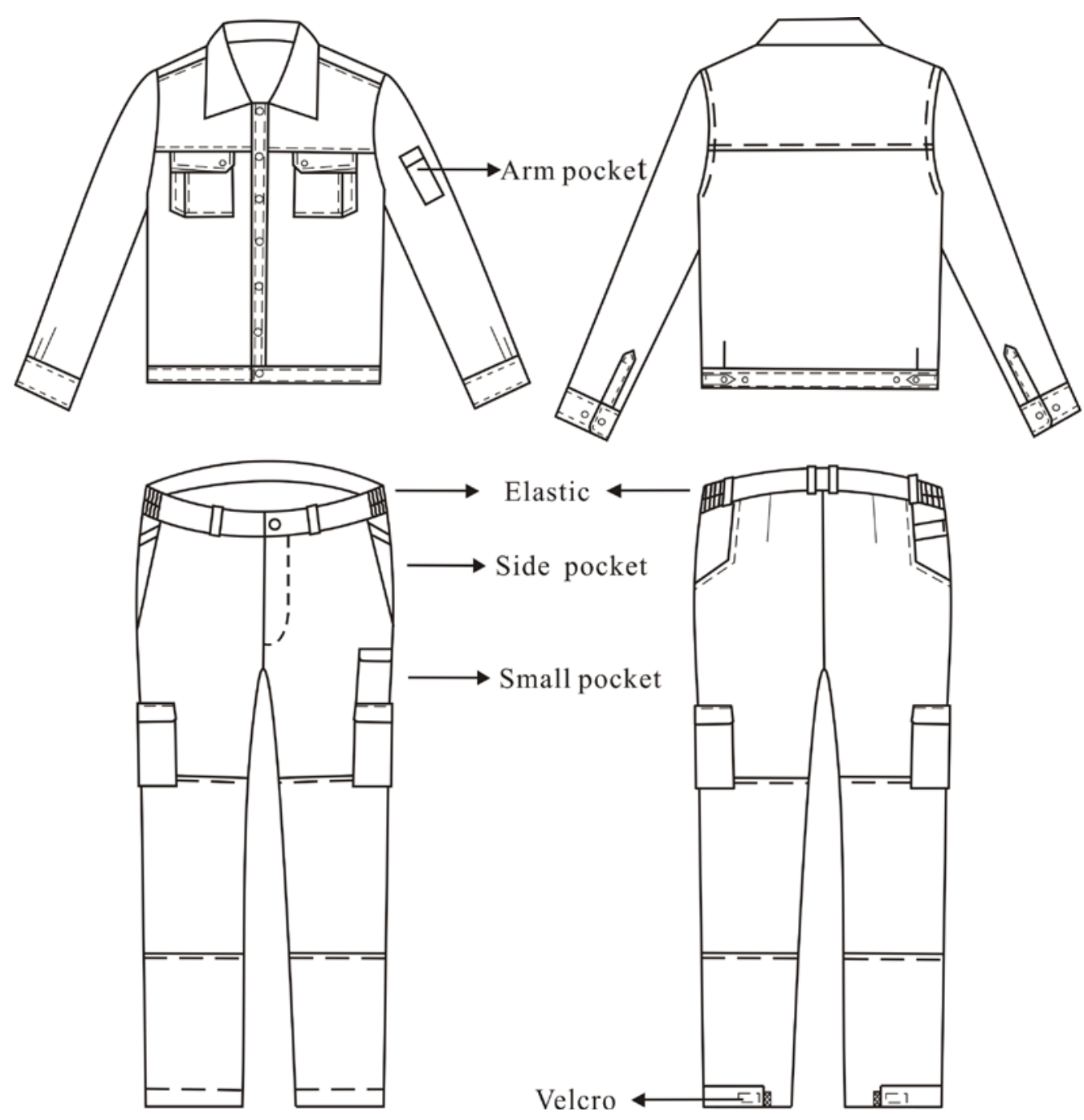

Figure 1. Design sketch of traditional emergency rescue suit. 
carry a lot of rescue tools, number of pockets is increased. The breast pocket of the coat was designed as a double-layer threedimensional pocket with pleats to increase the pocket capacity and designed close to the placket to facilitate the picking up and placing of items. The cover of the pocket was in the shape of trapezium with incomplete sealing, so that it could be used to place objects beyond the pocket length and easy to pick up and keep items. The side of the pocket was designed with zipper, so that objects are taken conveniently. Two pleats on the back of the jacket allowed for the human body structure and dynamic movement [18]. The common buckles are replaced at the cuff and pocket cover with snap buckles for easy opening and closing. The lower hem of the jacket was lengthened and designed with a curve to avoid the skin exposure of the back when the rescuers squat or bend over [17]. Further, the sleeves were equipped with loop fasteners.

Table 1. Basic parameters of fabric.

\begin{tabular}{|c|c|c|c|c|c|c|c|c|}
\hline Suit & Material & Color & Structure & $\begin{array}{c}\text { Tex of } \\
\text { yarns (tex) }\end{array}$ & $\begin{array}{c}\text { Thickness } \\
\text { (mm) }\end{array}$ & $\begin{array}{c}\text { Gram } \\
\text { weight } \\
\left(\mathrm{g} / \mathrm{m}^{2}\right)\end{array}$ & $\begin{array}{c}\text { Warp } \\
\text { density } \\
\text { (yarn/10 cm) }\end{array}$ & $\begin{array}{l}\text { Weft density } \\
\text { (yarn/10 cm) }\end{array}$ \\
\hline Jacket NC & $\begin{array}{c}\text { Polyester } \\
35 \% \\
\text { Cotton } \\
65 \%\end{array}$ & White & $1 / 2$ twill & 14.7 & 0.34 & 145 & 145 & 90 \\
\hline Jacket TC & $\begin{array}{c}\text { Polyester } \\
35 \% \\
\text { Cotton } \\
65 \%\end{array}$ & Blue & $1 / 2$ twill & 18.4 & 0.33 & 155 & 130 & 70 \\
\hline Pants NC & $\begin{array}{c}\text { Polyester } \\
35 \% \\
\text { Cotton } \\
65 \%\end{array}$ & Black & $1 / 2$ twill & 13.1 & 0.31 & 120 & 133 & 94 \\
\hline Pants TC & $\begin{array}{c}\text { Polyester } \\
35 \% \\
\text { Cotton } \\
65 \%\end{array}$ & Navy & $1 / 2$ twill & 19.6 & 0.45 & 220 & 152 & 72 \\
\hline
\end{tabular}

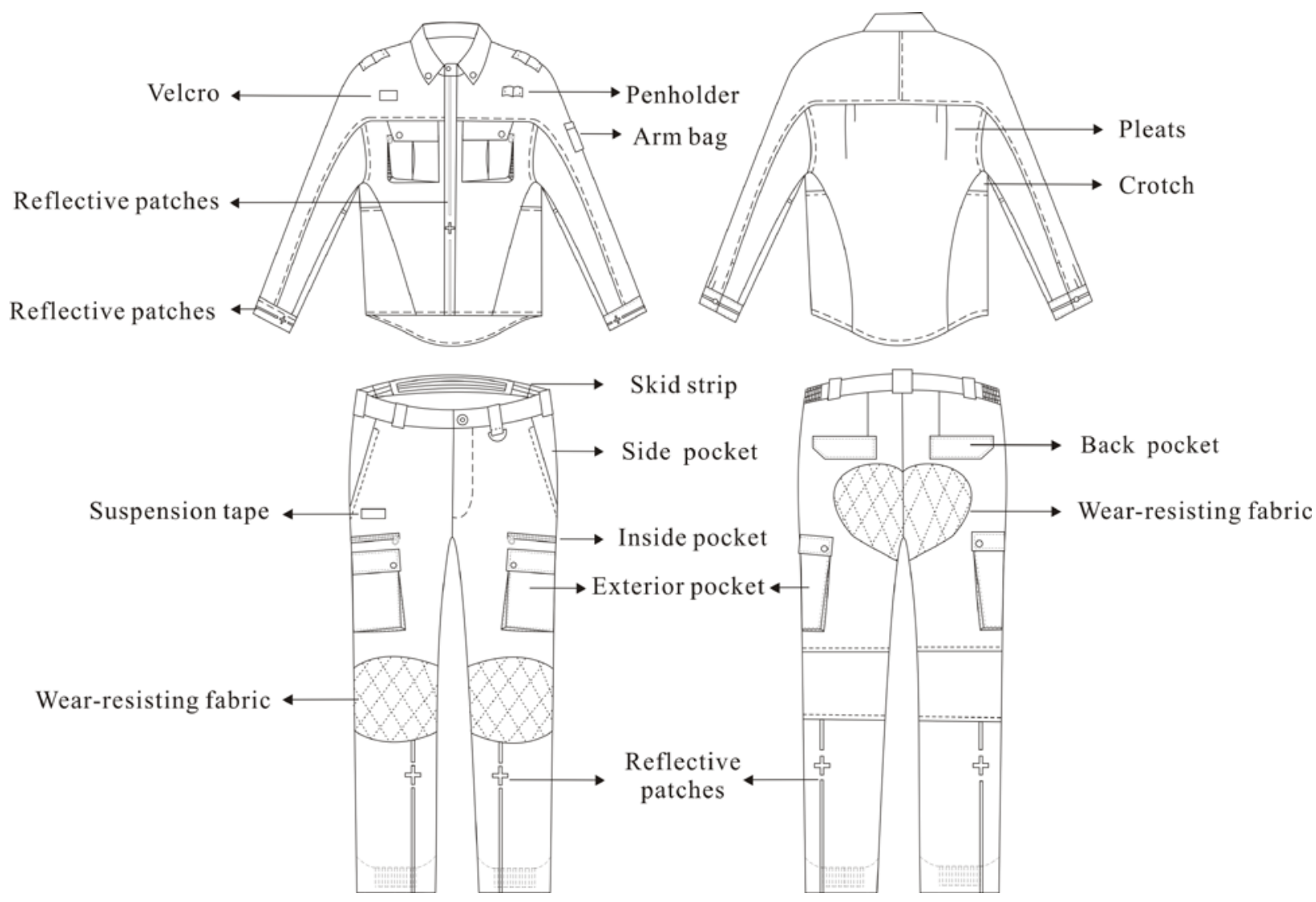

Figure 2. Design sketch of the new emergency rescue suit. 

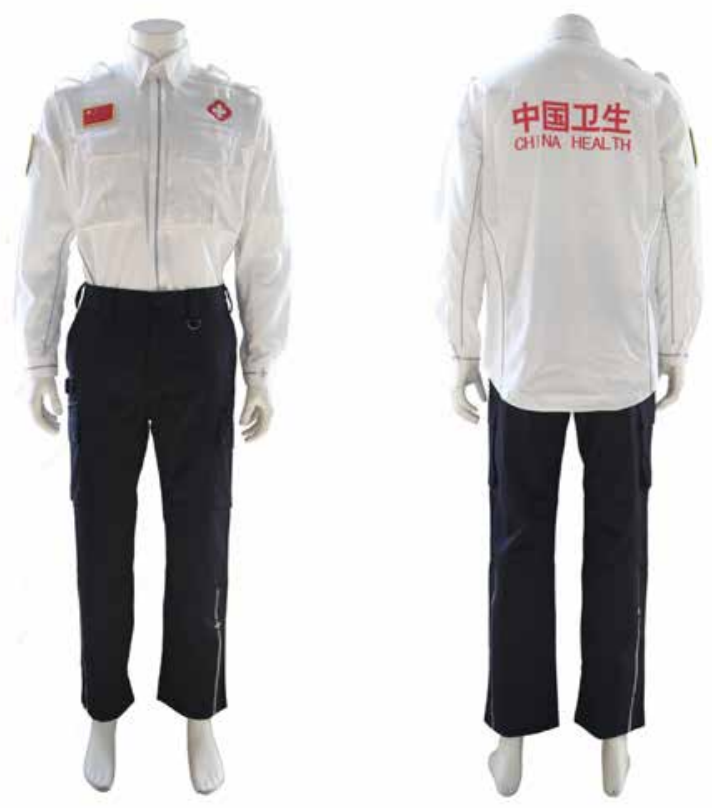

Figure 3. Photos of the new emergency rescue suit.

Moreover, the non-slip belt was designed at the waist to reduce the drop in the waist of the rescue pants. A layer of lining material added inside the pants and tightening the leg opening with rib cloth enhanced the comfort level and reduced the safety hazard caused by the upward movement of the pants. Apart from that, two symmetrical inside pockets (zipper seal) on the thighs were designed to increase the capacity of the pocket. In order to facilitate the picking up and placing of items, the inside pocket and exterior pocket of the rescue pants was designed with a tilt. In addition, reflective strips were designed at the front of the shirt, cuffs, sleeves, and side seam dividers to ensure the safety of rescuers in the dark.

\section{Methods}

\subsection{Participants}

Ten healthy male university students voluntarily participated in the trails. Their age, height, weight, and body mass index (BMI) were $21.7 \pm 1.6$ years, $177.6 \pm 1.5 \mathrm{~cm}, 66.5 \pm 4.9 \mathrm{~kg}$, and $21.1 \pm$ $1.6 \mathrm{~kg} / \mathrm{m}^{2}$, respectively. Prior to attending the trials, participants were briefed on the details of the trials. They were not allowed to do strenuous exercises and drink coffee/alcohol $24 \mathrm{~h}$ before participating in the experiments.

\subsection{Experimental clothing}

The traditional emergency rescue protective clothing (TC) and newly developed emergency rescue protective clothing (NC) as experimental clothing are selected for comparison.

\subsection{Environmental conditions}

Experiments were performed in an artificial climate chamber (manufacturer: ESPEC Inc., Osaka, Japan). The dimension was $4000 \times 3000 \times 2800 \mathrm{~mm}^{3}$ (length $\mathrm{x}$ width $\mathrm{x}$ height). Indoor air temperature was at $25^{\circ} \mathrm{C}$, relative humidity was kept at $50 \pm$ $5 \%$, and the indoor air velocity was maintained $<0.1 \mathrm{~m} / \mathrm{s}$.

Each subject subjected to two trials: TC and NC. They were blinded to TC and NC to avoid prejudice. All the tests were randomly assigned. Twenty tests were conducted for each experiment (i.e., 2 clothing conditions $\times 10$ subjects). They were asked to rest on an armless chair at room temperature for $30 \mathrm{~min}$ [19]. For each subject, the two trials were conducted at the same time of the day. Trails were conducted between 9 am and $6 \mathrm{pm}$, spaced by at least $24 \mathrm{~h}$.

\subsection{Test procedures}

\subsubsection{Clothing fit test}

Participants were asked to wear the experimental garment, and then allowed to enter into the chamber. The cuff, hem, waist, and leg opening position were marked in the upright state. Subjects are requested to perform four movements: arm-raising, bending, squatting, and leg-raising, and during the activities, marked the cuff, hem, waist and leg opening again, recorded the amounts of garment slippage at the four parts.

\subsubsection{Freedom of movement test}

The participants were asked to rest on an armless chair at room $\left(25^{\circ} \mathrm{C}\right.$ and $\left.50 \% \mathrm{RH}\right)$ for $30 \mathrm{~min}$, until thermal neutral conditions is achieved. After that, they dressed with experimental garments, entered into the chamber. During the trials, they are requested to perform a series of movements (Figures 4 and 5) in turn: arm-up, arm-up and jumping, hand-throwing, leg-raising, jumping, squatting, breast-holding, and bending. The eight movements were set according to the simplification and decomposition of rescue movements under the general rescue environment. Each action corresponded to different joint observation points [20]. Subjects were asked to finish the corresponding subjective questionnaire for each action, and observed the tension of clothing during the experiment, and made a record. After the test, the subjects came out of the chamber and took off the clothing.

Table 2. Rating scales of the local body subjective responses.

\begin{tabular}{|c|c|c|c|c|c|}
\hline Sensory characteristics & Very tight & tight & A bit tight & Not tight & Comfortable \\
\hline Scale sensory value & -3 & -2 & -1 & 0 & 1 \\
\hline
\end{tabular}




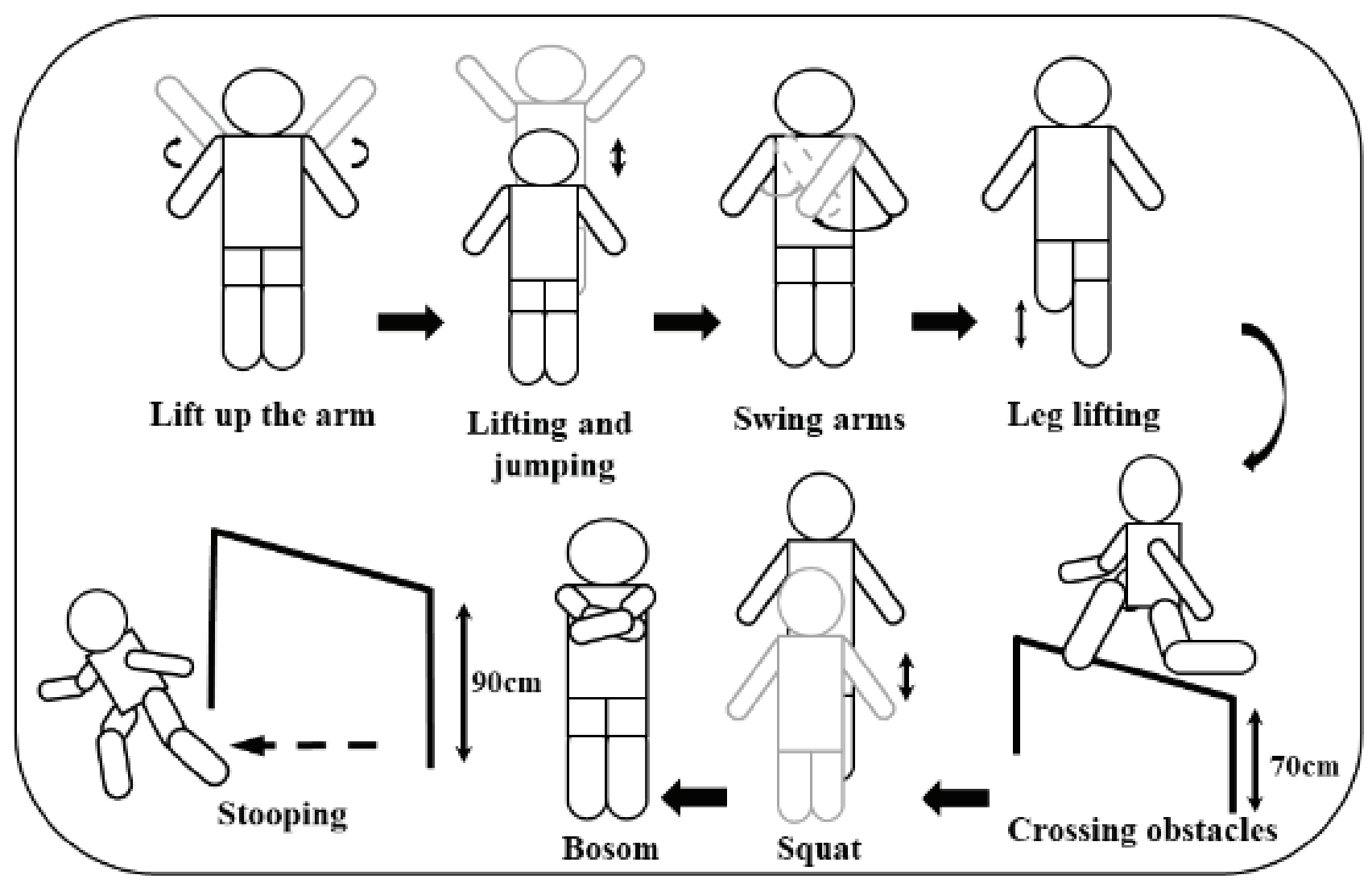

Figure 4. Flowchart of experimental action of local activity difficulty.
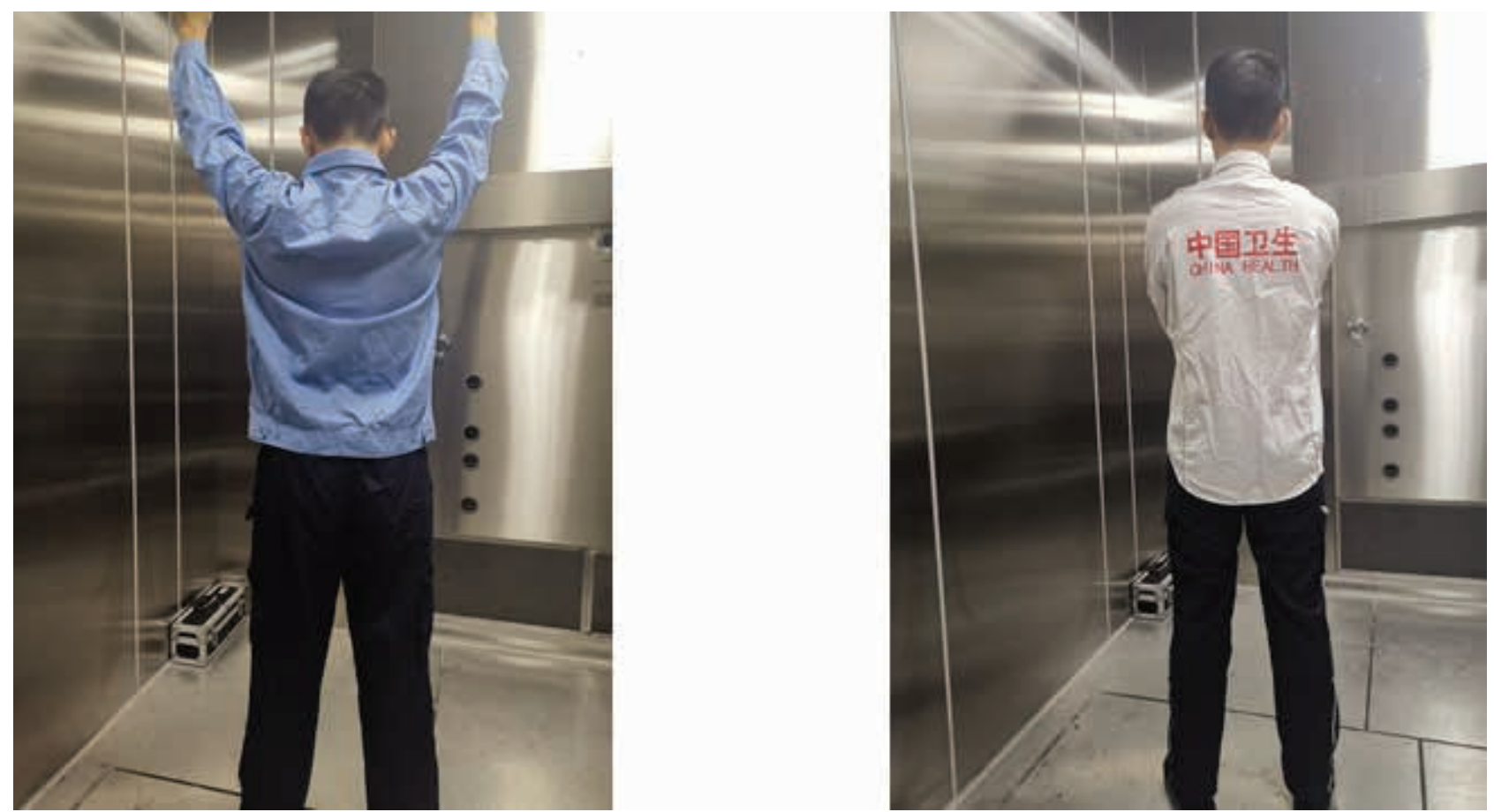

Figure 5. A male participant is wearing experimental clothing: the traditional emergency rescue suit (the left photo) and the new emergency rescue suit (the right photo).

Table 3. Rating scales of the smoothness sensation of taking and putting the rescue tools.

\begin{tabular}{|c|c|c|c|c|c|}
\hline Sensory characteristics & Very impeditive & Impeditive & Neutral & Smooth & Very smooth \\
\hline Scale sensory value & -2 & -1 & 0 & 1 & 2 \\
\hline
\end{tabular}



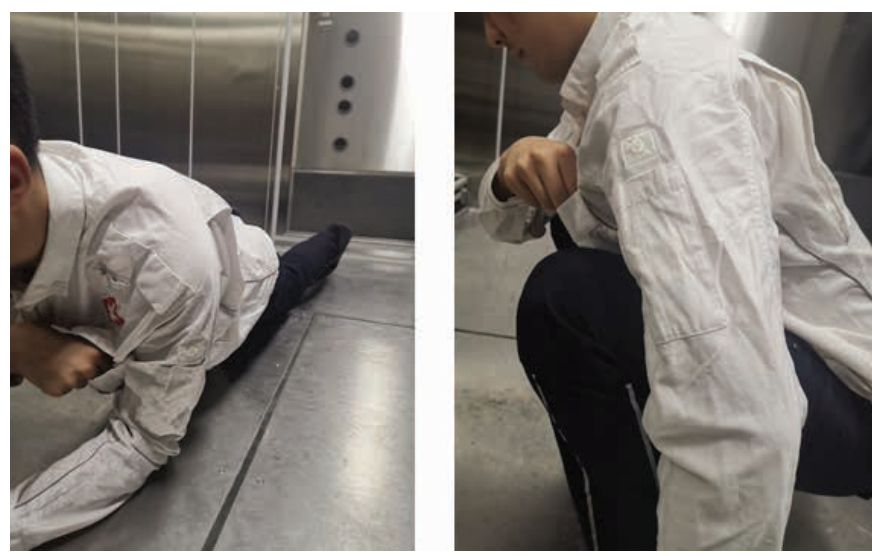

Figure 6. A male participant is wearing the new experimental clothing crawling (the left photo) and squatting (the right photo).

Rating scales used in this trail were shown in Table 2. A 5 -point tension sensation scale ranging from -3 ("Very tight") to +1 ("Comfortable") was used to record tension sensation of each movement. The values in the table were continuous and could be adjusted to give the subjects more choices, thus improving the accuracy of subjective evaluation value [21, 22].

\subsubsection{Pocket rationality test}

Please note that all the subjects were right-handed in this test. Before the experiment, they were asked to get familiar with the structure of the pockets of the rescue suit. After that, the subjects put on the NC, and then placed each rescue tool in the designated pocket (Figure 6). Only the left pocket was selected for experiment in this test. Subjects were asked to take and place each tool, respectively, while walking, running, spanning, squatting, and crawling. These five movements represent the physical movements commonly used or required in daily work of rescue team members. During the testing, the smoothness sensations of taking and putting the rescue tools were collected at each movement. Rating scales used in this trial were shown in Table 3. A continuous 5-point smoothness sensation scale ranging from -2 ("Very impeditive") to +2 ("Very smooth") was used to record smoothness sensation of taking and putting the rescue tools.

\subsection{Statistical analysis}

Data were presented as mean \pm SD (standard deviation) and the statistical analyses were performed using IBM SPSS version 22.0. Repeated-measures ANOVA was conducted to test whether independent variables (i.e., clothing [TC and $\mathrm{NC}$ ) significantly affected dependent variables such as perceptual parameters (e.g., tension sensation, smoothness sensation). Then t-test was applied to paired samples to compare the subjects' perceptual responses in fitness test, freedom of movement test, and smoothness test. Statistical significance was set as $p<0.05$ in all tests. Furthermore, fuzzy comprehensive evaluation method was used to evaluate the mobility and comfort of the main joints.

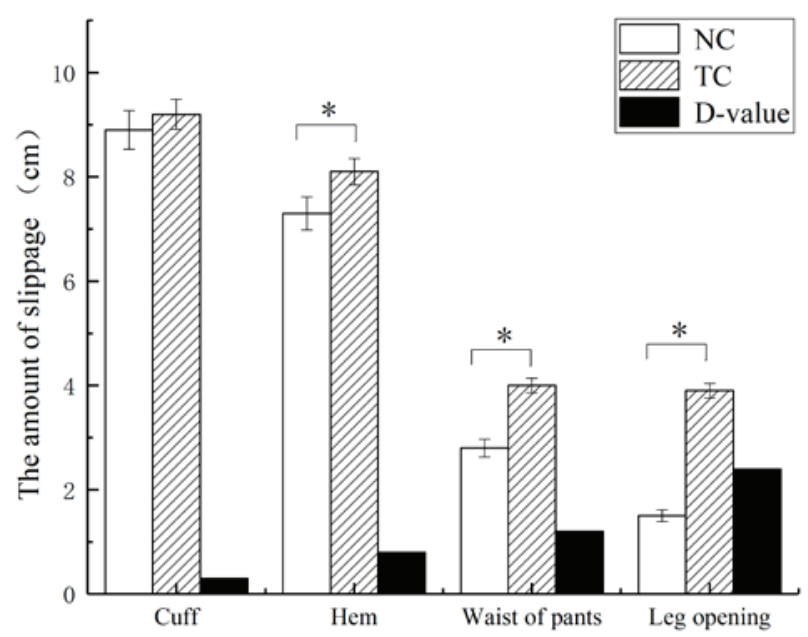

Figure 7. Measurements of slippage in different locations of the NC and the TC $\left({ }^{*} p<0.05\right)$.

\section{Results and discussion}

\subsection{Clothing fit}

Figure 7 shows the slippage at the cuff, hem, waist of pants, and leg opening of the two rescue suits. It can be observed that the amount of slippage at the hem in the NC and the TC were $7.3 \pm 0.32 \mathrm{~cm}$ and $8.5 \pm 0.25 \mathrm{~cm}$, respectively, with a mean difference of $1.2 \mathrm{~cm}(p<0.05)$, the amount of slippage at the waist of pants in the NC and the TC were $2.8 \pm 0.17 \mathrm{~cm}$ and $4 \pm 0.14 \mathrm{~cm}$, respectively, with a mean difference of $1.2 \mathrm{~cm}$ $(p<0.05)$, and the amount of slippage at the leg opening in the NC and the TC were $1.5 \pm 0.11 \mathrm{~cm}$ and $3.9 \pm 0.14 \mathrm{~cm}$, respectively, with a mean difference of $2.4 \mathrm{~cm}(p<0.05)$. But, there were no significant differences between TC and NC in the cuff's slippage $(p=0.055)$.

Table 4. Contrast of difficulty degree of local activity $\left({ }^{*}, p<0.05\right) 1$.

\begin{tabular}{|c|c|c|c|}
\hline \multirow{2}{*}{ Movements } & \multirow{2}{*}{ Parts } & \multicolumn{2}{|c|}{ Test scenarios } \\
\cline { 3 - 4 } & & NC & TC \\
\hline \multirow{2}{*}{ Lift up the arm } & Armpit & $-0.1^{*}$ & $-1^{*}$ \\
\cline { 2 - 4 } & Back & -0.6 & -1 \\
\hline Lifting and jumping & Knee & -0.2 & -0.5 \\
\hline Swing arms & Back & -1.6 & -1.5 \\
\hline \multirow{2}{*}{ Leg-lifting } & Thigh & $-0.3^{*}$ & $-1.4^{*}$ \\
\cline { 2 - 4 } & Knee & -0.5 & -0.7 \\
\hline Crossing obstacles & Crotch & $-0.5^{*}$ & $-1.3^{*}$ \\
\hline \multirow{2}{*}{ Squatting } & Hip & $-0.3^{*}$ & $-1^{*}$ \\
\cline { 2 - 4 } & Thigh & -0.2 & -0.5 \\
\cline { 2 - 4 } & Knee & $-0.5^{*}$ & $-1.55^{*}$ \\
\hline Bosom & Elbow & -0.3 & -0.7 \\
\hline Stooping & Back & $-0.3^{*}$ & $-1.3^{*}$ \\
\hline
\end{tabular}


Measurements of slippage could show clothing fit, when the elasticity of the fabric was low and the friction between the fabric and the skin was small [23]. As skin gets hurt very easily during emergency rescue process, the amount of slippage of the clothing should be minimized. The amount of slippage at the hem, waist of pants, and leg opening of the NC has been greatly reduced when compared with those of the TC (Figure 7). The main reason for these differences was that the lower hem of the NC was curve and lengthened, which avoided the skin exposure of the back. The NC had a non-slip belt at the waist to increase the friction. The NC also had a threaded inner lining to better tie the trousers legs and protect the wearer's ankles. Overall, the cuff still moved a lot when doing arm-up, without obvious optimization; it may be related to the arm position. Mullet [24]. pointed out that there was no significant difference at the wrist between the raglan sleeve's slippage and that of the set-in sleeves during arm-raising. However, the adoption of partition lines in the raglan sleeve allowed the upper extremities to get lifted and rotated freely [25]. Moreover, blind pursuit of reducing the amount of cuff's slippage reduced the freedom of movement of the arm.

\subsection{Freedom of movement}

The freedom of movement of corresponding body parts under eight movements when wearing the $\mathrm{NC}$ and the TC are shown in Table 4. When wearing the NC, the ratings of tension increase significantly on the thigh during leg-lifting, on the armpit during the lift up the arm, on the crotch when crossing obstacles, and on the hip and knee when squatting and compared with the ratings of the TC $(p<0.05)$. During the period of stooping, tensions of the back differed significantly between the NC and the TC $(p<0.05)$. Although the tension of the back did not differ significantly between the NC and the TC when swinging the arm, the ratings of tension were both under the lever of -1 (a bit tight), and obstructed the movement ( $\mathrm{TC}=-1.5, \mathrm{NC}=-1.6)$.

Comparisons showed that when participants wore TC, they felt significantly tighter on their thighs when raising their legs, tighter on their hips and knees when squatting, and tighter on their back when stooping. It meant that the NC was more suitable and flexible in terms of movement. The upper limb was the most flexible part of the human body, which could help and take part in the rescue work prominently. The structure of the sleeve was one of the factors that affected the range of movement of the upper limbs. Ni et al [26]. found that the design of raglan sleeve assembled with gusset had the large shoulder-movement angles significantly reduced the uncomfortable feelings of shoulder, back, upper arm, and armpit during activities. In this study, the raglan sleeves with partition lines and gussets (NC) were significantly more comfortable than set-in sleeve (TC). Moreover, the newly emergency rescue pants with increased back rise and gusset allowed easy leg movements.

It was beneficial when a high percentage of the movement allowances are added into the width of the back panels of the garment to enhance the dynamic comfort of a garment [25]. Based on that, a pleat was set into the yoke line to enhance the ease of back so that it could meet the requirements for human movement [27]. The NC with symmetrical pleats on the back had a significantly lower tightness than the TC when stooping. However, from the feedback of the subjects, the pleats of the back of NC significantly hindered movement, especially when they swung arms and folding arms. The reason may be related to the position and length of the back pleat and so further improvement is needed.

The fuzzy comprehensive evaluation method was used to evaluate the overall degree of freedom of movement of the two clothes. The eight motions designed in this experiment were chosen as factor set in evaluation. Further, all the eight factors were set with the equal weight value. Then the fuzzy evaluation sets were set up. Based on the theory of fuzzy mathematics, "worst, bad, moderate, good, best" are set up as the fuzzy evaluation set, and each word is converted into numerical variables " $0,1,2,3,4$ " separately. Finally, according to the product of the evaluation set matrix and the weight set matrix, comprehensive comfort evaluation values were calculated with the following formula [28]:

$Q_{i}=A^{\star} R_{i}$

where $A$ is the weight set matrix, $R_{i}$ is the evaluation sets matrix, $i=1$, 2 stands for new emergency rescue protective clothing and traditional emergency rescue protective clothing, respectively.

Comfort evaluation matrix of the two garments was as follows:

$\mathrm{Q} 1(=(0.014,0.1,0.263,0.623,0)$

$\mathrm{Q} 2(=(0.1,0.33,0.41,0.16,0)$

Based on maximum membership principle, the comfort evaluation results of NC were "good," and the comfort evaluation results of TC are "moderate." This illustrated that the mobility of NC was better when compared with the TC. Comfort evaluation value of each garment was calculated by using numerical matrix $R_{0}\left(=\mid \begin{array}{lllll}4 & 3 & 2 & 1 & 0 \mid \text { and conventional numerical }\end{array}\right.$ synthesis evaluation formula using the following equation [33]:

$$
P_{i}=R_{0}{ }^{\star} Q_{i}
$$

Calculation results were as follow: $P_{1}=2.43, P_{2}=1.63$. This suggested that the NC had better mobility, and the evaluation value was 0.8 higher than that of the TC.

\subsection{Pocket rationality}

Figure 8 shows the smoothness sensations of taking/putting rescue tools from/into the breast pocket while wearing the TC and the NC, respectively. Smoothness sensations of taking tools from the breast pocket of the NC were significantly higher than from the breast pocket of TC when walking, running, spanning, squatting, and crawling $(p<0.05)$. Similarly, smoothness sensations of putting tools into the breast pocket of 


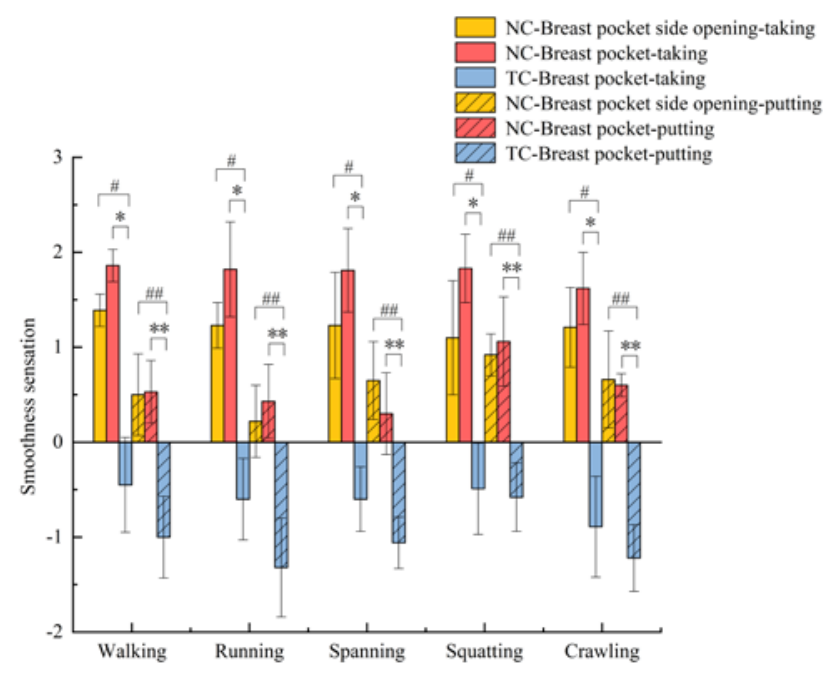

Figure 8. Smoothness sensation of taking rescue tools from breast pocket and putting rescue tools in breast pocket. $\# p<0.05$ (NC-Breast pocket side opening-taking vs. TC-Breast pocket-taking), ${ }^{*} p<0.05$ (NCBreast pocket-taking vs. TC-Breast pocket-taking), \#\#p < 0.05(NCBreast pocket side opening-putting vs. TC-Breast pocket-putting), ${ }^{* *} \mathrm{p}<0.05$ (NC-Breast pocket-putting vs. TC-Breast pocket-putting).

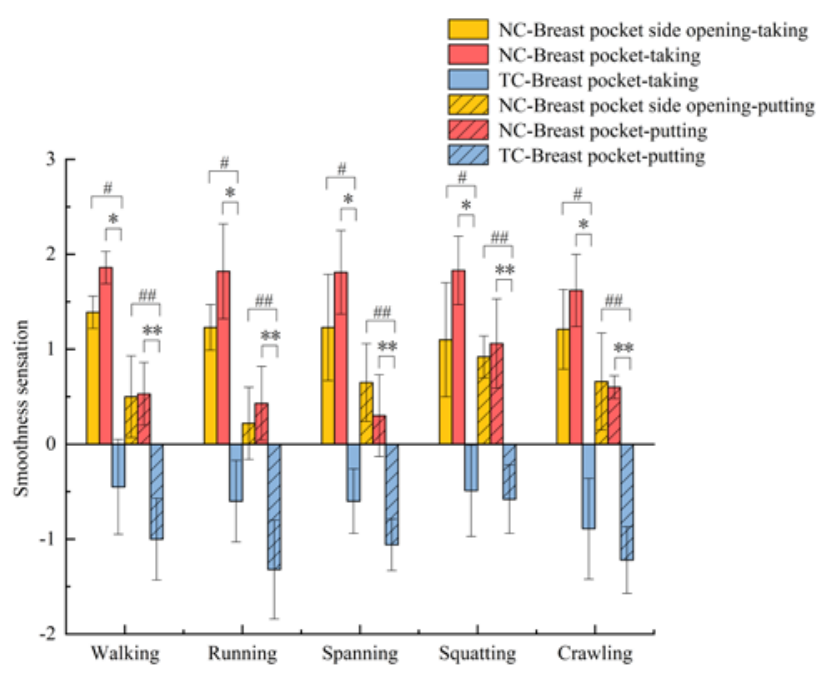

Figure 9. Smoothness sensation of taking rescue tools from inside pocket and small pocket and putting rescue tools in inside pocket and small pocket. Significant differences of taking and putting between NC and TC were marked in the graphs with symbols "\#" and "*”, respectively.

\section{A}

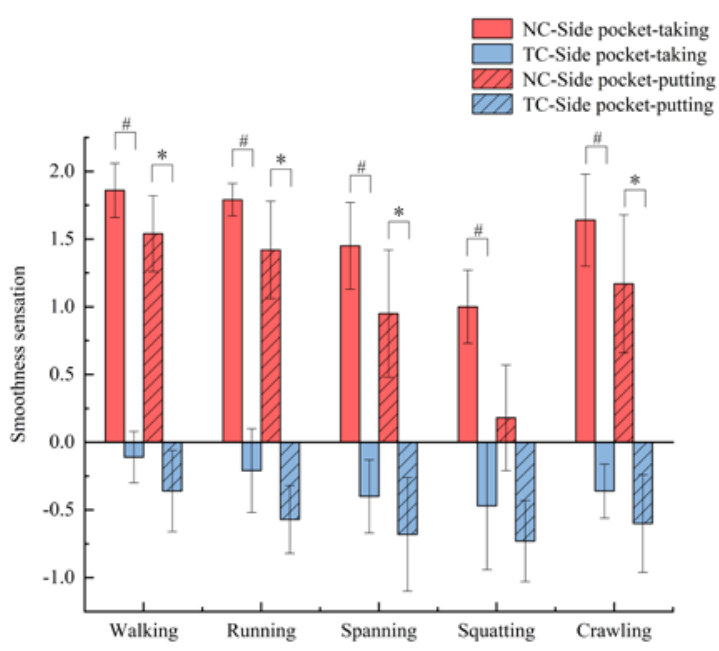

B

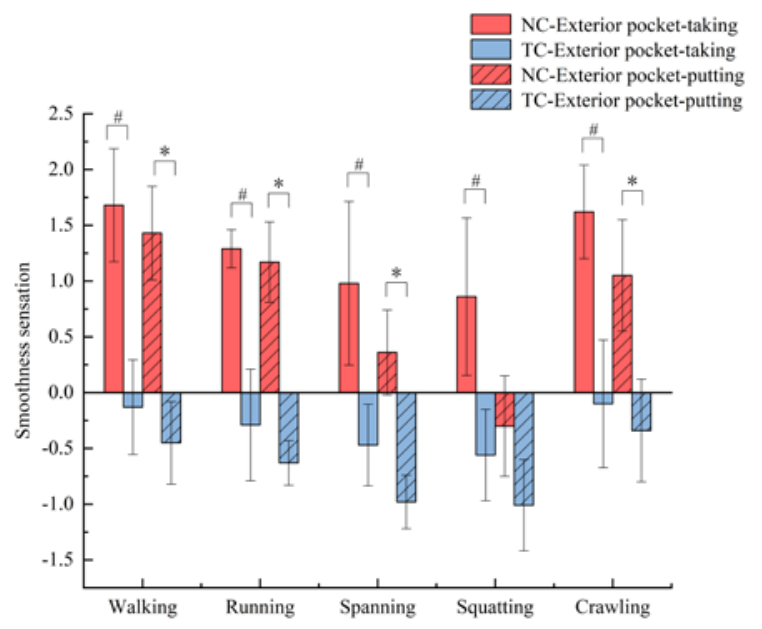

Figure 10. Smoothness sensation of taking rescue tools from side pocket (a) and exterior pocket (b), and putting tools in side pocket (a) and exterior pocket (b). Significant differences of taking and putting between NC and TC were marked in the graphs with symbols "\#" and "*”, respectively.

the NC were significantly higher than in the breast pocket of the TC while walking, running, spanning, squatting, and crawling $(p<0.05)$. The ratings of smoothness of taking rescue tools from breast pocket were always higher than putting in breast pocket in five movements. The ratings of smoothness of taking rescue tools from breast pocket of the NC were almost above the lever of 1 ("Smooth") in five movements. The ratings of smoothness of putting tools from the top of the breast pocket of the NC were higher than from the side while walking, running, spanning, and squatting. Also, taking tools from the top of the breast pocket of $\mathrm{NC}$ was easier than from the side of the breast pocket of the $\mathrm{NC}$ and the top of the breast pocket of the TC.

Figure 9 shows the smoothness sensations of taking rescue tools from the inside pocket of the NC and the small pocket of the TC and putting rescue tools into the inside pocket of the NC and the small pocket of the TC. There was significant difference in the smoothness of taking tools from the inside pocket and from the small pocket in five movements $(p<0.05)$. Smoothness sensations of putting tools in the inside pocket of the NC were significantly higher than in the small pocket of TC, when performing walking, running, spanning, squatting, and crawling $(p<0.05)$. The ratings of smoothness of taking and putting of NC were under the lever of 1 ("Smooth") when squatting.

The data of smoothness sensations of taking rescue tools from side pocket and exterior pocket and putting tools in side pocket and exterior pocket are shown in Figure 10. The smoothness sensation of taking tools from the side pocket of NC (Figure 10(a)) were significantly higher than TC in five movements $(p<0.05)$, and the smoothness sensation of putting tools in 
the side pocket of NC were significantly higher than TC when performing walking, running, spanning, and crawling $(p<0.05)$. Figure $10(b)$ showed that the smoothness sensation of taking tools from the exterior pocket of NC were significantly higher than TC in five movements $(p<0.05)$. Meanwhile, putting tools in the exterior pocket of NC were significantly easier than TC when performing walking, running, spanning, and crawling $(p<0.05)$. There was no significantly difference between NC and TC when putting tools in the side pocket and exterior pocket in squatting $(p>0.05)$.

Pockets of the protective clothing should have sufficient capacity and facilitate easy picking of items [29]. Hence, a double layer and three-dimensional breast pocket with pleats was designed close to the placket for the NC to increase the capacity, and replaced the common buckles at the pocket cover with snap buckles for easy opening and closing. Similarly, two symmetrical inside pockets (zipper seal) on the thighs were added in order to increase the capacity of pocket of the rescue pants. Further, the exterior pocket of the rescue pants was designed with a tilt and the inclination angle of the side pockets is designed larger to facilitate the picking up and placing of items. As hypothesized, it is observed that taking tools from the pocket of NC was obviously easier than from the pocket of TC, and putting tools in the pocket of NC was also smoother. Moreover, it was smoother to take tools from the upper opening of breast pocket of NC than from the side opening when performing five movements. During walking, running, and squatting, placing objects from the upper opening to the chest pocket of NC was smoother than placing objects from the side opening. When spanning and crawling, it was smoother to put tools in the breast pocket of NC from the side opening than from the upper opening. This was due to the arm being displayed at different angles under various motion states [30]. Overall, the pocket design of NC is more convenient to take items in five movements, while the placement of items is still not smooth when squatting and it needs to be corrected.

\section{CONCLUSIONS}

In this study, the design of emergency rescue protective clothing was optimized, and series of tests were conducted to verify whether the optimal design scheme improved comfort of rescue suits. Results demonstrated that the new-designed emergency rescue protective clothing had better cloth fit and improved dynamic comfort, and when the storage capacity of pocket is increased, the position and angle design of the pocket made it easier to take and place the rescue tools. But the pleats on the back of jacket and the pockets of trousers in NC need further improvement. In general, the new-designed emergency rescue protective clothing improved the wearing comfort and rescue efficiency. The study aims to provide some theoretical and practical basis for the improvement of comfort of emergency rescue protective clothing.

\section{ACKNOWLEDGMENTS}

The authors wish to acknowledge the support from the volunteers for their assistance in the experiments. This work was supported by China Postdoctoral Science Foundation $<2020 T 130255>$, MOE (Ministry of Education in China) Project of Humanities and Social Sciences under Grant $<20$ YJCZH063>, the open fund of Key Laboratory of Clothing Design and Technology (Donghua University), Ministry of Education, China<KLCDT2020-02>.

\section{References}

[1] Olness, K., Mandalakas, A., Pairojkul, S., Holsinger, E., Bothe D., Herran, M. (2008). The children in disasters project: Addressing the special needs of children in manmade and natural disasters. Pediatrics, 121(2), 115.

[2] Leaning, J., Guha-Sapir, D. (2013). Natural disasters, armed conflict, and public health. New England Journal of Medicine, 369(19), 1836-1842.

[3] Lucia, B. (2020). Natural catastrophes in times of economic accumulation and climate change [Press release]. Web site: $\quad$ https://www.swissre.com/institute/research/sigmaresearch/sigma-2020-02.html

[4] Zhang, S. (2019). On the mine rescue team's own casualty analysis. Mining Equipment, 5, 82-83.

[5] Liu, D., Li, C. (2019). Influencing factors and avoidance strategies of firefighters' casualties. Journal of Henan Polytechnic University (Social Sciences), 20(2), 54-58.

[6] Zhai, L., Lin, X., Xu, J., Wang, Y., Li, J. (2016). Principles and hierarchy design of protective clothing for earthquake disaster search and rescue team members. International Journal of Clothing Science and Technology, 28(5), 624633.

[7] Zhang, M., Bai, J. (2012). Significance and application thoughts on international rescue uniform logo in response to natural disasters. China Personal Protective Equipment, 4, 25-27.

[8] Bell, J. L., Gardner, L. I., Landsittel, D. P. (2000). Slip and fall related injuries in relation to environmental cold and work location in above-ground coal mining operation. American Journal of Industrial Medicine, 38(1), 40-48.

[9] Huck, J. (1991). Restriction to movement in fire-fighter protective clothing evaluation of alternative sleeves and liners. Applied Ergonomics, 22(2), 91-100.

[10] Li, J., Guan, W., Wei, H. (2005). Performance evaluation and its application and development of functional protective clothing. China Personal Protective Equipment, 6, 22-25.

[11] Ruckman, J. E., Murray, R., Choi, H. S. (1999). Engineering of clothing systems for improved thermos-physiological comfort: the effect of openings. International Journal of Clothing Science and Technology, 11(1), 37-52.

[12] Hejazi, S. M., Kadivar, N., Sajjad, A. (2016). Analytical assessment of woven fabrics under vertical stabbing - The role of protective clothing. Forensic Science International, 259, 224-233.

[13] António, M., António, R. (2009). Personal protective clothing and safety of firefighters near a high intensity fire front. Fire Safety Journal, 44, 514-521. 
[14] Havelka, A., Kus, Z. (2006). The Physiological properties of smart textiles and moisture transport through clothing fabric. In: Fan, J. (Ed.). The 6th International Thermal Manikin and Modeling Meeting. Hong Kong (China). pp. 355-362.

[15] Standardization Administration of the People's Republic of China. (2008). GB/T 335.1-2008: Standard sizing systems for garments - Men. China Standard Press (China).

[16] Adabms, P. S., Slcum, A. C., Keyserling, W. M. (1994). A model for protective clothing effects on performance. International Journal of Clothing Science and Technology, 6(4), 6-16.

[17] Li, X. (2005). Study on the pattern and process design of the front cardigan of the shirt. Shanghai Textile Technology, 33(7), 13-14.

[18] Li, C., Liang, J. (2015). Analysis of the influence of structural design of protective clothing on comfort. The Literature Review, 4, 16-18.

[19] Fanger, P. O. (1970). Thermal comfort: Analysis and applications in environmental engineering. McGraw-Hill (New York, NY).

[20] Chou, C., Son, S., Tochihara, Y. (2009). Effects of wearing trousers or shorts under firefighting protective clothing on physiological and subjective responses. Applied Ergonomics, 12(2), 63-71.

[21] Wang, Y., Wang, X., Li, J., Zhang, X., Chen, Y. (2007). Development of the evaluation scale of perceptual comfort of clothing. Journal of Textile Research, 28(5), 104-108.

[22] Tian, M., Wang, Y., Zhang X., Zhang, Z. (2013). Comfortergonomics evaluation and optimization of thermal protective clothing. Journal of Donghua University (Natural Science), 39(6), 754-759.

[23] Zhang, W., Fang, F. (2015). Ergonomics of clothing. (2nd ed.). Donghua University Press (Shanghai, China).

[24] Mullet, K. K. (1991). The effect of shoulder position on four sleeve/bodice structure. (Doctoral dissertation, Virginia State University, Blacksburg, USA).
[25] Liu, C., Kennon, R. (2005). Improving the compromise between clothing style and dynamic comfort from sleeve construction. Research Journal of Textile and Apparel, 9(3), 34-39.

[26] Ni, J., Zhang, S., Wang, W., Han, Y. (2020). Effect of sleeve structure design on flexibility of arm movement. Journal of Donghua University (Nature Science), 46(1), 41-46.

[27] Zhao, W. (2016). Study on the comfortable structure design and evaluation of summer combat clothing. (Master's thesis, Beijing Institute of Clothing Technology, Beijing, China).

[28] Zhou, Q. (2011). The study of vehicle comfort based on virtual prototype and ergonomics (Master's thesis, Wuhan University of Technology, Wuhan, China).

[29] Zhu, G., Zhao, J. (2014). Structural design and pattern of fine parts of clothing. Donghua University Press (Shanghai, China).

[30] Kamalha, E., Zeng, Y., Mwasiagi, J., Kyatuheire, S. (2013). The comfort dimension: A review of perception in clothing. Journal of Sensory Studies, 28(6), 423-444.

[31] Xin, L., Li, J., Wang, Y. (2011). Research on the design pattern of protective clothing. Journal of Textile Research, 32(11), 119-125.

[32] Li, H., Zhang, W. (2007). Progress in research on clothing function. Journal of Textile, 28(8), 117-119.

[33] Camenzind, M. A., Dale, D. J., Rossi, R. M. (2007). Manikin test for flame engulfment evaluation of protective clothing: historical review and development of a new ISO standard. Fire and Materials, 31(5), 285-295.

[34] Guan, X. P., Zhang, L. Y., Gao, Y. H. (2006). Nutritional status and three nutrients intake analysis of China international search and rescue team. Journal of Nursing, 13(7), 17-19.

[35] Lin, X., Zhai, L., Zhang, M., Wang, Y., Li, J. (2016). Ergonomic evaluation of protective clothing for earthquake disaster search and rescue team members. International Journal of Clothing Science and Technology, 28(6), 820829. 